\title{
Outcomes in patients with heart failure with regard to statin therapy
}

\section{(D)Amina Godinjak ${ }^{1 *}$, CMiralem Đešević', DAmer Iglica ${ }^{2}$, (1)Adis Kukuljac ${ }^{3}$}

'Eurofarm Centar Medical Clinic, Sarajevo, Bosnia and Herzegovina

${ }^{2}$ Clinical Center University of Sarajevo, Sarajevo, Bosnia and Herzegovina

${ }^{3}$ General Hospital Sarajevo, Sarajevo, Bosnia and Herzegovina

\section{RECEIVED:}

July 29, 2019

ACCEPTED:

September 16, 2019

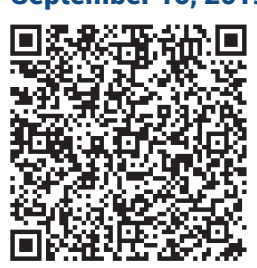

$\square$ Cardiologia Croatica 2019;14(9-10):222.
KEYWORDS: heart failure, statin therapy, outcome.

CITATION: Cardiol Croat. 2019;14(9-10):222. | https://doi.org/10.15836/ccar2019.222

*ADDRESS FOR CORRESPONDENCE: Amina Godinjak, Fra Anđela Zvizdovića 1, 71000 Sarajevo, Bosnia and Herzegovina. / Phone: +38761187010 / Email: aminagodinjak@gmail.com

ORCID: Amina Godinjak, https://orcid.org/0000-0002-3697-8006 • Miralem Dešević, https://orcid.org/0000-0001-8760-6192 Amer Iglica, https://orcid.org/0000-0002-4677-8489 • Adis Kukuljac, https://orcid.org/0000-0002-4900-5094

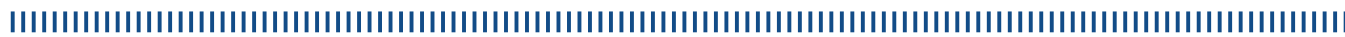

Objective: The aim of this study was to investigate whether statin therapy influenced outcomes in patients with acute heart failure (HF).,1,2

Patients and Methods: Eighty five patients with diagnosis of HF were included in the study. For each patient the following data were obtained: gender, age, comorbidities and medications. New York Heart association (NYHA) class for heart failure was determined by physician evaluation and left ventricle ejection fraction (LVEF) was determined by echocardiography. Outcome points were: hospitalization, in-hospital death, mortality after 6 months, 1 year and 2 years. All-cause mortality included cardiovascular events or worsening heart failure.

Results: Mortality after 6 months, 1 year and 2 years was the most frequent in patients without statin therapy with a statistically significant difference $(p=0.001)$. Progression of HF accounted for $31.7 \%$ of mortality in patients without statin therapy.

Conclusion: Statin therapy is associated with substantially better long-term outcomes in patients with HF.

LITERATURE IIIIIIIIIIIIIIIIIIIIIIIIIIIIIIIIIIIIIIIIIIIIIIIIIIIIIIIIIIIIIIIIIIIIIIIIIIIIIIIIIIIIIIIIIIIIIIIIIIIIIIIII

1. Alehagen U, Benson L, Edner M, Dahlström U, Lund LH. Association between use of statins and outcomes in heart failure with reduced ejection fraction: prospective propensity score matched cohort study of 21864 patients in the Swedish Heart Failure Registry. Circ Heart Fail. 2015 Mar;8(2):252-60. https://doi.org/10.1161/CIRCHEARTFAILURE.114.001730

2. Preiss D, Campbell RT, Murray HM, Ford I, Packard CJ, Sattar N, et al.The effect of statin therapy on heart failure events: a collaborative metaanalysis of unpublished data from major randomized trials. Eur Heart J. 2015 Jun 21:36(24):1536-46. https://doi.org/10.1093/eurheartj/ehv072 